\title{
MULTI-SCALE METHODOLOGY TO MAP GREY AND GREEN STRUCTURES IN URBAN AREAS USING PLÉIADES IMAGES AND EXISTING GEOGRAPHIC DATA
}

\author{
Jean Nabucet ${ }^{1}$, Simon Rougier ${ }^{2}$, Julien Deniau ${ }^{2}$, Léo Vétillard ${ }^{1}$, Emilie Hanson ${ }^{3}$, Omar Benarchid ${ }^{3}$, Eléonore Wolff ${ }^{3}$, \\ Laurence Hubert-Moy ${ }^{1}$, Anne Puissant ${ }^{2}$
}

\author{
1: LETG-Rennes COSTEL UMR CNRS 6554, Université Rennes 2, France; jean.nabucet@univ-rennes2.fr \\ 2: LIVE UMR CNRS 7362, Université de Strasbourg, France. \\ 3: IGEAT, Université Libre de Bruxelles, Belgium.
}

\begin{abstract}
Résumé
L'identification et le suivi des extensions urbaines ainsi que la préservation des écosystèmes en milieu urbain sont devenus des enjeux majeurs de nos sociétés. Dans un contexte de consommation d'espace toujours plus importante et de croissance constante de la population urbaine, la pression sur les milieux semi-naturels en milieu urbain est de plus en plus forte. Les enjeux autour des trames vertes et bleues comme la demande sociale de "nature " imposent de développer des méthodes novatrices et adaptées à ce type de milieux pour maintenir ou augmenter la biodiversité dans les zones urbaines de la plupart des villes européennes. De nombreuses études ont déjà été menées sur la cartographie et l'analyse des villes européennes et leurs évolutions au moyen de données de télédétection mais une méthodologie consolidée et reproductible manque encore. Dans le cadre du projet VALI-URB, une méthodologie multi-scalaire basée sur des images Pléiades et des données géographiques existantes (bases de données vectorielles de type OSM et BDTOPO ${ }^{\circledR}$ IGN) est proposée pour cartographier les surfaces bâties et vertes dans les zones urbaines et périurbaines. L'objectif est montrer l'intérêt d'utiliser une information d'occupation et d'utilisation des sols dérivée des images Pléiades combinées à des données vecteurs pour cartographier de manière semi-automatique les structures grises et vertes à l'échelle locale (1/10 000) par une classification orientée-objets. Les premiers résultats sont présentés sur deux villes de taille moyennes aux formes urbaines différentes: Strasbourg et Rennes (France).
\end{abstract}

Mots-clés: morphologie urbaine, imagerie Pléiades, Données auxiliaires, classification d'images orientées-objets

\begin{abstract}
Identification and monitoring of urban fabric and preservation of existing ecosystems have become major issues to maintain or increase biodiversity in areas under urban influence in most of European cities. While many studies have shown the interest of using optical remotely sensed data for that purpose, a consolidated and reproducible methodological framework was still missing. In this context, a multi-scale methodology has been proposed in the framework of the project VALI-URB to map built-up and vegetated land features in urban and suburban areas based on Pléiades images and existing ancillary data (vector databases or the Open Street Map database). The objective of this paper is to highlight the interest of using land cover/use maps derived from Pléiades images and vector databases to semi-automatically characterize grey and green infrastructures at a scale of 1:10,000. First results are presented on two medium-sized cities with different urban forms: Strasbourg and Rennes (France).
\end{abstract}

Keywords: urban structure, Pléiades imagery, ancillary data, object-based image classification

\section{Introduction}

Improving our knowledge on the urban patterns with their grey and green structures and their dynamics at multiple spatial scales (from the urban block to the morphological urban zone) plays an important role for a wide range of applications, such as urban planning and management (Herold et al., 2005), disaster management (Okada et al., 2000), or energy consumption modelling in urban environments (Heiple et al., 2008). Many studies have mapped and analysed European cities and their evolution using optical remote sensed data but a consolidated and reproducible methodological framework is still missing. In the context of the VALI-URB Project, a multi-scale methodology based on Pléiades images and existing ancillary data (vector databases or the Open Street Map - OSM database) has been proposed to map built-up and vegetation land features in urban and suburban areas.
The mapping of grey and green elements at local scale performed with an object-based image analysis using Pléiades satellite images with a generic methodology on two test sites (Strasbourg, Rennes) is provided. The second section presents the study site and data, and the third one details the flowchart of the general methodology. Section 4 shows first results obtained on Strasbourg and Rennes. Conclusions and discussion of the results are expressed in section 5 .

\section{Study sites and datasets}

Two medium-sized cities with different urban forms have been chosen to apply the standardized methodological approach (Figure 1). Both cities present several typical morphological urban characteristics representative of some western urban areas. 


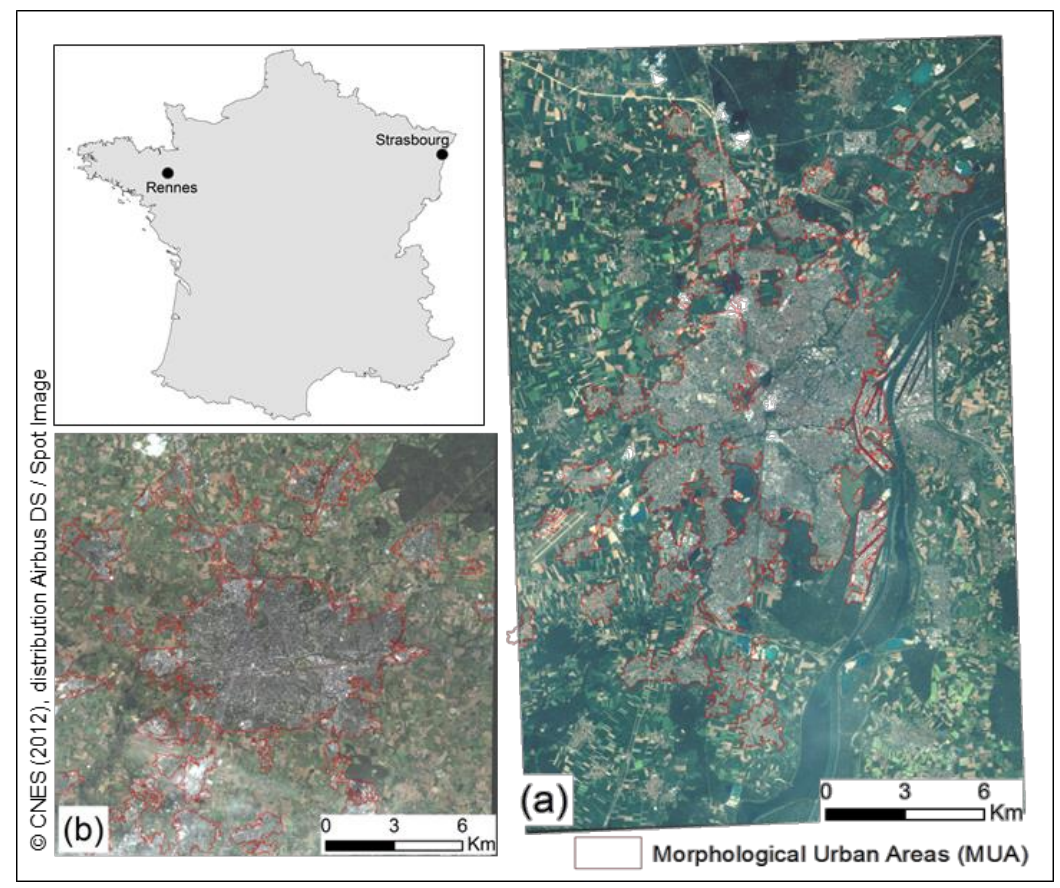

Figure 1: Location of the study sites. Pléiades images are displayed as a true color composition (RGB).

Strasbourg is a compact urban city of 415,000 inhabitants (2013) which covers an area of $316 \mathrm{~km}$ with a density of 1498 inhab. $/ \mathrm{km}$. This city is organized as a concentric dense city centre inherited from the MiddleAges with surroundings organized in some rings (Figure 1a). Rennes is a multi-nodal city of 473,187 inhabitants (2013) surrounded by a green-belt and covering an area of $705 \mathrm{~km}$ with a density of 587 inhab./ km. The city is structured as a polycentric city (Figure 1b). Both cities are submitted to a gradual urbanisation process since the last century with an urban sprawl achieving the third ring (Strasbourg) and the peripheric cities (Rennes). Thus, several urban patterns or Urban Fabrics (UF) can be observed in both cities along a gradient of urbanization from the city-centre and its suburbs (Figure 2).

A bundle (MS + P) Pléiades image has been acquired in both cities during leaf-on period (Figures 1a and $1 \mathrm{~b}$ and Table 1). Radiometric and atmospheric corrections are applied to Pléiades images using the 6S model (Second Simulation of a Satellite Signal in the Solar Spectrum vector code) proposed by Vermote et al. (1997). Corrections are performed with the Orfeo Tool Box (OTB) using the Optical Calibration/6S module. Both images are orthorectified by the French National Geographic Institute. Pan-sharpened orthoimages with a $0.5 \mathrm{~m}$ spatial resolution are created based on the combination of panchromatic and multi-spectral bands.

\begin{tabular}{|c|c|c|c|}
\hline Study site & $\begin{array}{c}\text { Acquisition } \\
\text { date }\end{array}$ & $\begin{array}{c}\text { Resampled } \\
\text { Spatial } \\
\text { resolution }\end{array}$ & $\begin{array}{c}\text { Cloud } \\
\text { cover } \\
(\%)\end{array}$ \\
\hline Rennes & $10 / 04 / 12$ & $2 \mathrm{~m}, 0.5 \mathrm{~m}$ & $10-15$ \\
\hline Strasbourg & $08 / 14 / 12$ & $2 \mathrm{~m}, 0.5 \mathrm{~m}$ & $5-10$ \\
\hline
\end{tabular}

Table 1: Characteristics of Pléiades images (MS Multispectral / P - Panchromatic).

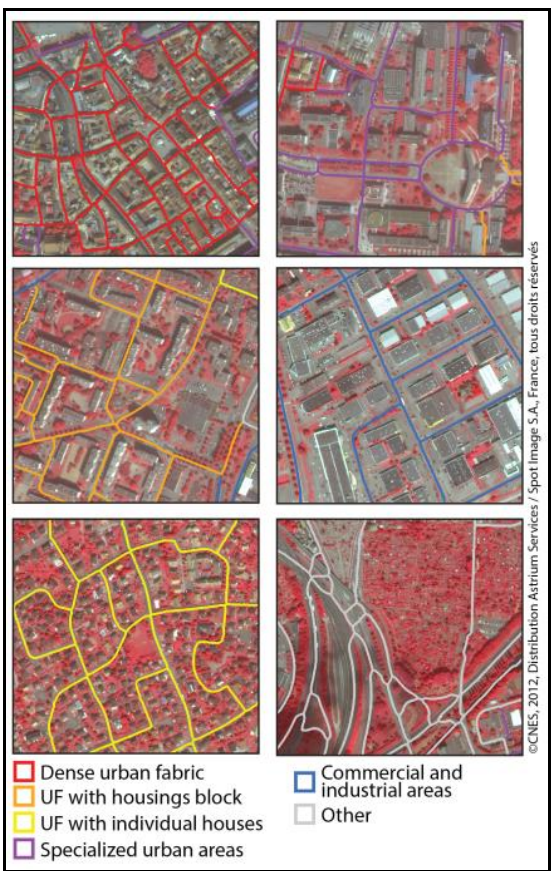

Figure 2: Typology of urban patterns (urban fabrics).

A list of urban objects (Table 2) was firstly defined to map the urban areas at 1/10,000 according to (Puissant et al., 2005). In this study, urban objects are defined as homogeneous units in the Pléiades image by two attributes: (1) the first one refers to the spectral response of the object (material) and (2) the second refers to its spatial dimension (shape) (Puissant, 2003). Based on this definition, twenty-three urban objects were defined. These objects were grouped into three object categories (Table 2-level 1: water, vegetation, artificial/mineral) according to classical and standardized land cover nomenclature (Corine Land Cover or Urban Atlas datasets). 


\begin{tabular}{|c|c|c|c|}
\hline Level 1 & Level 2 & Level 3 & Level 4 \\
\hline \multirow{6}{*}{1 Water } & \multirow{2}{*}{11 water surface } & 111 pond / lake & \\
\hline & & 112 swimming pool & \\
\hline & \multirow{4}{*}{12 linear water } & 121 brook & \\
\hline & & 122 small river & \\
\hline & & 123 big river & \\
\hline & & 124 channel & \\
\hline \multirow{8}{*}{2 Vegetation } & \multirow{4}{*}{21 tree /shrub } & 211 isolated tree (crown surface) & $\begin{array}{l}2111 \text { isolated deciduous tree } \\
2112 \text { isolated coniferous tree }\end{array}$ \\
\hline & & 212 tree group (copse) & $\begin{array}{l}2121 \text { deciduous tree group } \\
2122 \text { coniferous tree group } \\
2123 \text { mixed tree group }\end{array}$ \\
\hline & & 213 tree alignment & $\begin{array}{l}2131 \text { deciduous tree alignment } \\
2132 \text { coniferous tree alignment } \\
2133 \text { mixed tree alignment }\end{array}$ \\
\hline & & 214 other & \\
\hline & \multirow{4}{*}{22 grass } & 221 square / rectangular grass & \\
\hline & & 222 square linear grass & \\
\hline & & 223 round grass & \\
\hline & & 224 grass with other form & \\
\hline \multirow{3}{*}{$\begin{array}{l}3 \text { Artificial/ } \\
\text { mineral }\end{array}$} & 31 above ground surface & $\begin{array}{l}311 \text { orange roof building } \\
312 \text { dark grey roof building } \\
313 \text { light grey/white roof building }\end{array}$ & \\
\hline & 32 ground surface & $\begin{array}{l}321 \text { dark to light grey surface } \\
322 \text { orange surface } \\
323 \text { 'green' mineral surface } \\
324 \text { beige surface }\end{array}$ & \\
\hline & 33 linear element & $\begin{array}{l}331 \text { linear dark to light grey } \\
332 \text { linear beige }\end{array}$ & \\
\hline \multicolumn{4}{|l|}{$\begin{array}{l}4 \text { Shadow } \\
5 \text { Cloud/haze }\end{array}$} \\
\hline d/haze & & & \\
\hline
\end{tabular}

Table 2: Nomenclature of urban objects in four level (in grey - typology used for the land cover classification).

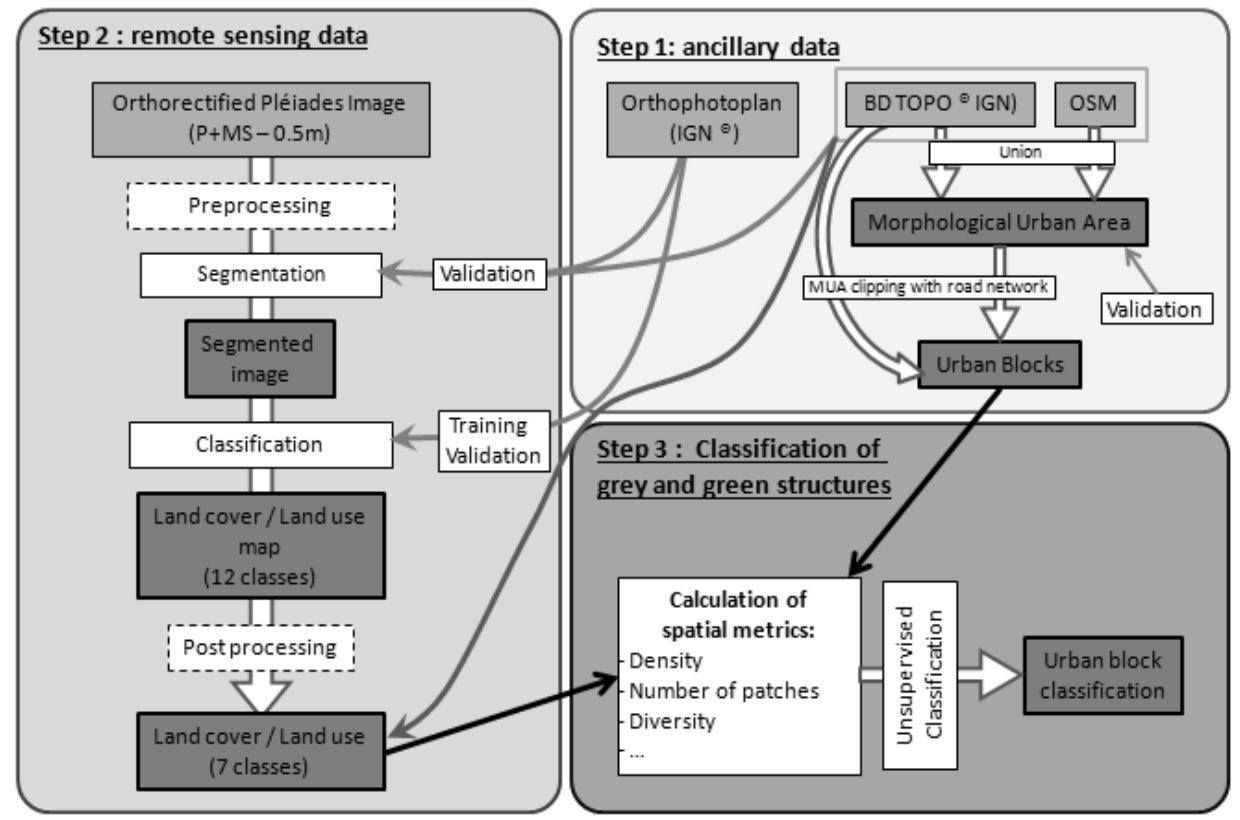

Figure 3: Flowchart of the general methodology.

\section{Methodology}

The proposed methodology is organized in three steps (Figure 2) and follows a bottom-up approach in order to be close to the visual interpretation process. The first step (Figure 3 - step 1) concerns the extraction of the Morphological Urban Area (MUA) and the delineation of 'urban blocks' based on ancillary data. A protocol based on Loriot (2008) was proposed to extract impervious surfaces (housing, communication ways, commercial or industrialized zones). The MUA was firstly delineated using (1) the built-up layer derived from the combination of the BD TOPO $₫$ IGN and the OSM databases and (2) the road, railway and hydrographic network layers, extracted from the BD TOPO ${ }^{\circledR}$ IGN database. In this study BD TOPO ${ }^{\circledR}$ IGN database is considered as the reference layer to be updated by the OSM database. Comparison of the two 
layers allowed us to extract the elements present only in the OSM database, to validate them by photointerpretation and update the BD TOPO ${ }^{\circledR}$ IGN database. Each limit (Figure 1) is validated using MUA's limits derived from aerial photographs and cadastres provided by the urban agencies of both cities. Then, units called 'urban blocks' were delineated in using the MUA limits previously defined and the main roads, rivers and all the railways.

In the second step, the MUA is classified using an object-based image analysis (Figure 3 - step 2). The Pléiades images are firstly segmented before being classified to identify the urban objects defined in the nomenclature (Table 2 in grey). Three supervised classification algorithms were tested. The segmentation and classification results are then evaluated. The training and validation schemes proposed are detailed in section 3.1. Section 3.2 explains the segmentation and classification algorithms. In the step 3, the grey and green structures are analysed at the 'urban block' scale (Figure 3, step 3). This analysis is based on a series of metrics classically used in landscape ecology. Eight spatial metrics (\% of land cover per class, number of patches, mean and standard deviation of patch size, patch and edge density, shape index, Shannon index) are calculated on the land cover classification (Figure 3, Step 2) at the scale of the urban blocks. These blocks were previously classified into six classes of urban fabrics. In Rennes, a supervised photo-interpretation process is applied to build these classes. In Strasbourg, a regional land use database is available ${ }_{B} C I G A L$ (Figure 2). This exploratory analysis has to allow classifying urban blocks into urban fabrics. In this paper, only preliminary results of unsupervised classification of these urban blocks based on four metrics are presented. Validation step is performed using the Kappa Index (Congalton, 1991).

\subsection{Training and validation steps}

A rigorous statistical accuracy assessment generally requires suitable reference data, an appropriate sampling scheme and independence between the training and validation datasets (Congalton, 1991). Training and validation samples are generated through a stratified random sampling scheme adapted from Puissant et al. (2014). The stratification is based on an urbanization index, which represents the complexity of a city with several density levels. The urbanization index was built using three land cover classes ('vegetation areas' $\left(A_{V}\right)$, 'non-vegetation areas' $\left(A_{N V}\right)$ and water areas $\left(A_{w}\right)$ ). Vegetation areas are extracted in thresholding a NDVI computed from the Pléiades images. Water surfaces were derived from the BD TOPO ${ }^{\circledR}$ IGN database and other areas that did not belong to $A_{V}$ or $A_{w}$ are considered as non-vegetation areas. Study zones are sub-divided into squared plots with a respective area $A_{T}$ of $0.25 \mathrm{~km}^{2}(500 \mathrm{~m} \times 500 \mathrm{~m})$. For each plot the urbanization index $I_{u}$ is computed using:

$$
I_{U}=\frac{A_{N V}-A_{V}}{A_{T}-A_{w}}
$$

This urbanization index ranges from -1 for the totally vegetation surfaces to 1 for the totally artificialized plots. The proposed index is classified by quantiles in five classes in order to obtain diverse and representative samples. This type of discretisation is particularly adapted, as each class is equally represented. For the two most urbanized plots, a random selection of 1000 segments per class is labelled. For the three least urbanized plots, only 600 segments are considered since their spatial organization is less complicated and composed of objects fewer. Classification methods prsented in next part are then evaluated by crossvalidation technique. $2 / 3$ of labelled segments are randomly chosen and considered for the training, and $1 / 3$ for the validation. Kappa indexes are also calculated to assess classification results.

\subsection{Segmentation and classification methods}

The Pléiades images are segmented using the Multiresolution segmentation algorithm of eCognition ${ }^{\circledR}$ software (Baatz and Shäpe, 2000; Burnett and Blasche, 2003). The optimal parameters (shape, compactness, smoothness) are performed using two methods: an unsupervised method, the Estimate Scale Parameter (ESP) tool (Drăguţ et al., 2010; eCognition ${ }^{\circledR}$ software, 2012) and a supervised method, the distance index (Levine and Nazif, 1985; Clinton et al., 2010). The supervised method is validated using one hundred and eighty reference polygons randomly selected from the OSM or the BD TOPO ${ }^{\circledR}$ IGN databases, or digitized from the orthophotoplan (IGN@) (Belgiu and Drăguţ, 2014). In total, 28 parameter combinations were tested to determine the optimal scale, smoothness and compactness values (Tables 3 and 4).

\begin{tabular}{|c|c|c|}
\hline Scale & shape & Compactness \\
\hline 70 & $0.5 ; 0.9$ & $0.5 ; 0.9$ \\
\hline 80 & $0.5 ; 0.9$ & $0.1 ; 0.5 ; 0.9$ \\
\hline 90 & $0.5 ; 0.9$ & $0.1 ; 0.5 ; 0.9$ \\
\hline 100 & $0.5 ; 0.9$ & $0.5 ; 0.9$ \\
\hline 110 & $0.5 ; 0.9$ & $0.5 ; 0.9$ \\
\hline 120 & $0.5 ; 0.9$ & $0.5 ; 0.9$ \\
\hline
\end{tabular}

Table 3: Test of segmentation parameters.

\begin{tabular}{|c|c|c|c|}
\hline Site & Scale & Shape & Compactness \\
\hline Rennes & 80 & 0.9 & 0.5 \\
\hline Strasbourg & 90 & 0.9 & 0.1 \\
\hline
\end{tabular}

Table 4: Optimal segmentation parameters.

Three supervised classification methods are applied to the segmented images: K-Nearest Neighbor (KNN) (Cover and Hart, 1967), Random Forest (RF) (Breiman, 2001) and Support Vector Machine (SVM) (Vapnik, 1998). The classifications are performed using 14 image features with spectral information (mean and standard deviation values), indexes (NDVI, MSAVI, and brightness), geometric information (area, compacity, asymmetry) and textural parameters (Homogeneity and entropy). Spatial post-processing is then conducted by crossing the classifications with the ancillary data (Figure 2, step 2). Seven classes of landcover are considered: building from OpenStreetMap or from BD TOPO $\AA$ IGN, network (roads and railways) and water from BD TOPO ${ }^{\circledR} I G N$, agricultural parcel from 'Registre Parcellaire Graphique' (RGP), tree, grass and other artificialized surfaces with classification of Pléiades images. 


\section{Results}

\subsection{Step 1: Morphological Urban Area with ancillary data}

The maps of the MUA created with the protocol (Figure 2, Step1) are very close to the MUAs provided by the planning agencies in both cities (Figure 4). For instance, the MUA of Rennes shows a slight difference (less than 10\%) between the surfaces of the two MUAs. The main differences can be explained by scattered housing along some roads, which were aggregated during the layer elaboration. These results show that this semi-automatic method for mapping the MUA can be reproducible and should be adaptable to different types of city.

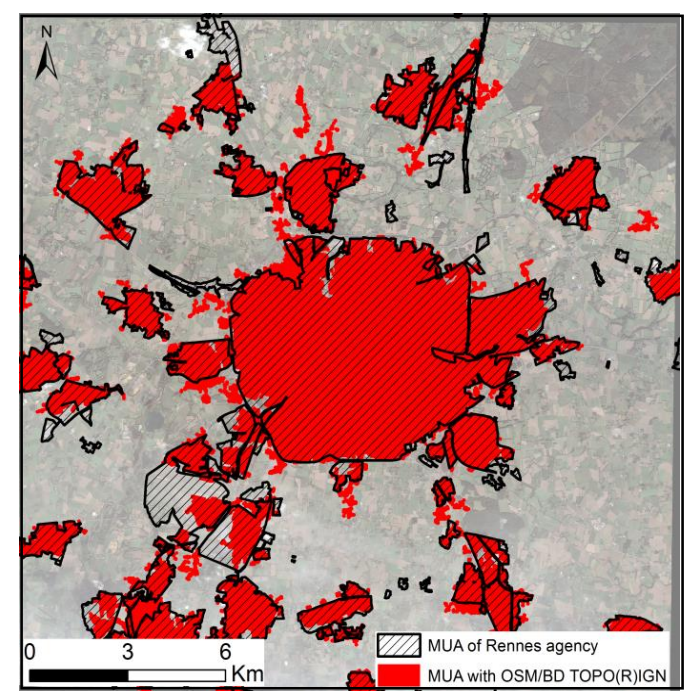

Figure 4: Comparison of MUAs on Rennes The MUA produced using OSM/ BD TOPO ${ }^{\circledR}$ IGN databases and the MUA provided by the planning agency (AUDIAR).

\subsection{Step 2: Classification results}

Kappa values for the three classification algorithms are satisfactory (Table 5) with values always superior to 0,7 . Though, RF and SVM classifiers give better results than the KNN technique. The best classification result is obtained with the SVM classifier for Strasbourg (Kappa: 0.8 ) and with the RF classifier for Rennes (Kappa: $0.79)$. RF classifier and SVM show greater robustness in some class discrimination (shadows/water, shadow/gray object) (Figure 5). Shadow discrimination requires more specific methods, the three classification methods showing the same limits to correctly extract them.

\begin{tabular}{|c|c|c|c|}
\cline { 2 - 4 } \multicolumn{1}{c|}{} & KNN & SVM & $\begin{array}{c}\text { Random } \\
\text { Forest }\end{array}$ \\
\hline Strasbourg & 0.72 & 0.80 & 0.78 \\
\hline Rennes & 0.73 & 0.78 & 0.79 \\
\hline
\end{tabular}

Table 5: Classification Kappa values.

The performances of classification by class expressed with the F-measures appear unequal (Table 6). In general, F-measures are significantly higher than 0.7 which express good performances for classification model for both cities. But mistakes exist for classes like scrubs in the two sites due to misclassification with wooded elements. This class is very under-represented in the landscape and few examples are taken into account for the training step. Other classes, like orange areas in Rennes or herbaceous vegetation in Strasbourg, have same problems. Most classifiers under class-imbalance, like SVM or RF, tend to be biased in favour of the majority class, and vice versa, and may underestimate the number of cases belonging to the minority class (He and Garcia, 2009).

\begin{tabular}{|c|c|c|}
\cline { 2 - 3 } \multicolumn{1}{c|}{} & $\begin{array}{c}\text { Strasbourg } \\
\text { (SVM) }\end{array}$ & $\begin{array}{c}\text { Rennes } \\
\text { (RF) }\end{array}$ \\
\hline Water bodies & 0,968 & 0,839 \\
\hline Wooded areas & 0,914 & 0,87 \\
\hline Scrubs & 0,142 & 0 \\
\hline Orange area & 0,869 & 0,25 \\
\hline Herbaceous areas & 0,591 & 0,817 \\
\hline Grey area & 0,853 & 0,874 \\
\hline White areas & 0,667 & 0,776 \\
\hline Beige areas & 0,757 & 0,704 \\
\hline Crops & 0,879 & 0,825 \\
\hline Bare soils & 0,84 & 0,853 \\
\hline Shadows & 0,808 & 0,766 \\
\hline Clouds & 0,958 & 0,889 \\
\hline
\end{tabular}

Table 6: Classification F-measures.

The nomenclature presented in Table 2 is organized in 4 levels of detail. In this work, the classification results show that objects are well classified at Level 2 for vegetation and water classes, and at Level 3 for the class "artificial areas". However, the classification failed to identify classes at level 4 . This is probably due to the difficulty to extract shape indexes from the segmented images that could be used to refine the classification.

\subsection{Step 3: Exploratory analysis of urban blocks and classification}

The series of metrics are computed at two scales: the MUA and the urban blocks. First, the distribution of urban fabrics is not the same in the two cities (Table 6). Dense urban fabrics and individual residential areas are more present in Strasbourg whereas specialized urban areas are more numerous in Rennes. Some errors about the identification of urban blocks can be observed because urban block classes were assigned differently in the two cities, i.e. by photo-interpretation and using a regional land cover database respectively for Rennes and Strasbourg. This explains why some small blocks delimited by roads, like places or roundabouts, are affected to urban classes whereas this kind of objects are classified as other objects in the case of Rennes.

At the urban fabric scale, part of land cover objects in urban blocks appears similar in both cities (figure 6). Only the urban fabric with individual houses presents different patterns with more "tree vegetation" in Strasbourg and "grass" in Rennes. Trees in this block are bigger and fewer in Strasbourg than in Rennes. Artificial areas are also larger in Strasbourg, which can be explained by the data source used to of assign the urban blocks to a given class. Moreover, buildings are larger but less numerous in Rennes due to the size of urban blocks in this city (Table 6). Urban fabrics in Rennes appear more fragmented for all blocks probably owing to the classification results. The combination of the three metrics presented in figure 6 allows differentiating urban fabrics based on their composition. First result of unsupervised classification of urban blocks is presented in Figure 7 . The result is encouraging with an overestimation of two classes: 'others surfaces' and mixed UF. 


\begin{tabular}{|c|c|c|c|c|c|c|}
\cline { 2 - 7 } \multicolumn{1}{c|}{} & \multicolumn{2}{c|}{ Mean Area (ha) } & Proportion of each class (\%) & \multicolumn{2}{c|}{ Number of patches } \\
\cline { 2 - 7 } \multicolumn{1}{c|}{} & Rennes & Strasbourg & Rennes & Strasbourg & Rennes & Strasbourg \\
\hline $\begin{array}{c}\text { Dense urban } \\
\text { fabrics }\end{array}$ & 0.83 & 1.05 & 1 & 4 & $88(2 \%)$ & $520(11 \%)$ \\
\hline $\begin{array}{c}\text { UF with housing } \\
\text { blocks }\end{array}$ & 1.08 & 1.86 & 12 & 8 & $651(13 \%)$ & $494(11 \%)$ \\
\hline $\begin{array}{c}\text { UF with individual } \\
\text { houses }\end{array}$ & 1.04 & 1.80 & 18 & 26 & $993(19 \%)$ & $1746(39 \%)$ \\
\hline $\begin{array}{c}\text { Specialized urban } \\
\text { areas }\end{array}$ & 2.51 & 1.20 & 24 & 6 & $570(11 \%)$ & $296(6 \%)$ \\
\hline $\begin{array}{c}\text { Industrial and } \\
\text { commercial areas }\end{array}$ & 5.45 & 2.68 & 16 & 13 & $177(3 \%)$ & $304(3 \%)$ \\
\hline
\end{tabular}

Table 6: Composition of urban blocks.
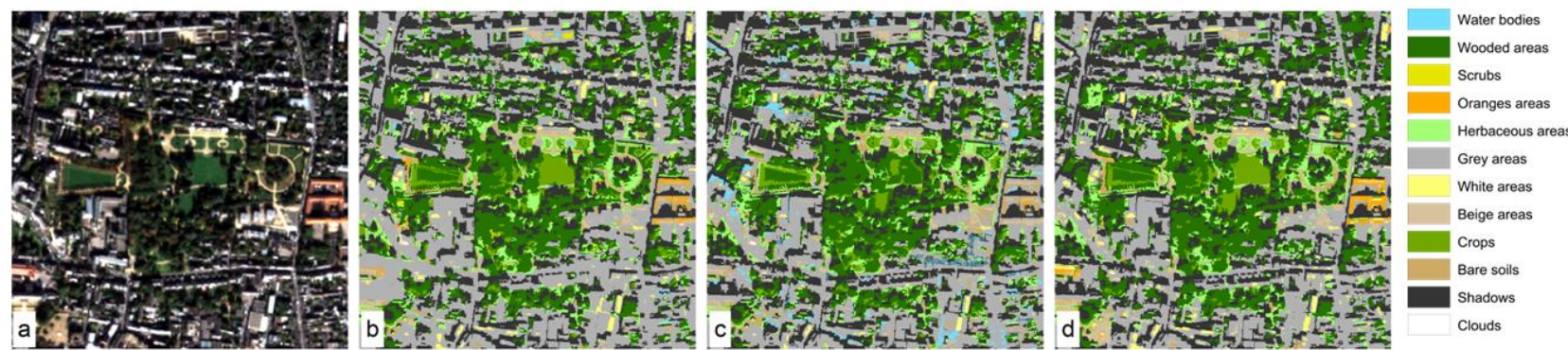

Figure 5: Comparison of the classified images produced in Rennes (a) RGB original image of Rennes, (b) classification map using RF, (c) ) classification map using KNN, (d) ) classification map using SVM.

\begin{tabular}{|c|c|c|c|c|c|}
\hline & Dense urban fabrics & $\begin{array}{l}\text { UF with housing } \\
\text { blocks }\end{array}$ & $\begin{array}{l}\text { UF with individual } \\
\text { houses }\end{array}$ & $\begin{array}{l}\text { Specialized urban } \\
\text { areas }\end{array}$ & $\begin{array}{l}\text { Industrial and } \\
\text { commercial areas }\end{array}$ \\
\hline 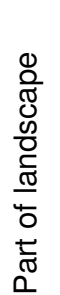 & $\begin{array}{l}40.0 \\
300\end{array}$ & 30.0 & $<$ & & \\
\hline 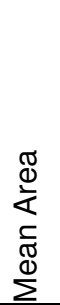 & $\begin{array}{l}5000 \\
4000 \\
3000 \\
2000 \\
2000 \\
0.0\end{array}$ & 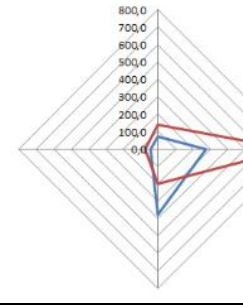 & & 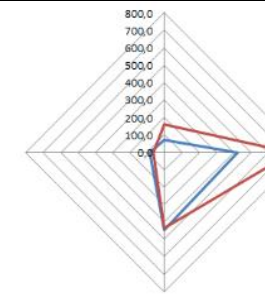 & 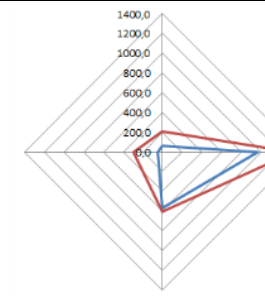 \\
\hline 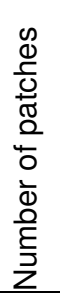 & & & & & \\
\hline & Grass & & $\begin{array}{l}\text {-Rennes } \\
\text {-Strasbourg }\end{array}$ & & \\
\hline
\end{tabular}

Figure 6: Composition of urban fabrics characterized by three metrics. 


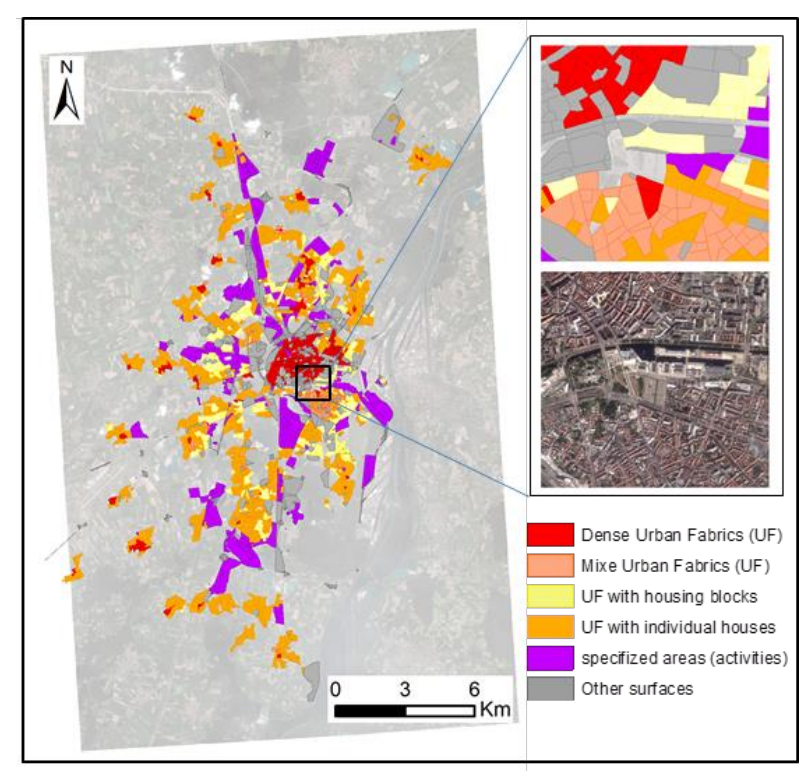

Figure 7: First result of unsupervised classification of urban blocks in Strasbourg with four metrics $(\%$ of landcover per class, number of patches, standard deviation of patches and Shannon index).

\section{Conclusion and perspectives}

The proposed methodology in this research based on Pléiades imagery allows producing some information related to MUA and urban fabrics related to grey and green structures. The proposed methods using existing data at different levels in the process produce multiscale information and showed preliminary good results on Strasbourg and Rennes. Some developments on Brussels have done same results. The spatial analysis of urban fabric could be also completed by others indexes and has to be evaluated on a great number of urban fabrics. However, the same type of approach could also be applied to cities characterized by other morphology development by adapting features selection and composition.

\section{Acknowledgements}

This research is co-funded by the STEREO II programme of BELSPO and contributed to the RTU (Pléiades (C) CNES (2012), distribution Airbus DS / Spot Image), ORFEO Accompaniment Program (CNES). Thanks to the IGN services for the orthorectification of the images, to the Rennes Planning Agency (AUDIAR) for giving us access to MUA data and to CIGAL for the Land cover Regional database in Strasbourg.

\section{References}

Baatz M., Schäpe A., 2000. Multiresolution Segmentation: an optimization approach for high quality multi-scale image segmentation. in: Strobl, J. (Ed.). XII., 12-23.

Belgiu M., Drăguţ L., 2014. Comparing supervised and unsupervised multiresolution segmentation approaches for extracting buildings from very high resolution imagery. ISPRS Journal of Photogrammetry and Remote Sensing, 96(0), 67-75.

Breiman L., 2001. Random Forests. Machine Learning, 45, 5-32.
Burnett C., Blaschke T., 2003. A multi-scale segmentation/object relationship modelling methodology for landscape analysis. Ecological Modelling 168, 233-249.

Clinton N., Holt A., Scarborough J., Yan L., Gong P., 2010. Accuracy Assessment Measures for Objectbased Image Segmentation Goodness. Photogrammetric Engineering and Remote Sensing, 76(3), 289-299.

Congalton R.G., 1991. A review of assessing the accuracy of classifications of remotely sensed data. Remote Sensing of Environment 37(1), 35-46.

Cover, T., Hart, P., 1967. Nearest neighbor pattern classification. Information Theory, IEEE Transactions on Information Theory, 13(1), 21-27.

Drăguţ L., Tiede D., Levick S.R., 2010. ESP: a tool to estimate scale parameter for multiresolution image segmentation of remotely sensed data. International Journal of Geographical Information Science 24(6), 859-871.

He H., Garcia E.A., 2009. Learning from Imbalanced Data. IEEE Transactions on Knowledge and Data Engineering 21(9), $1263-1284$.

Heiple S., Sailor D.J., 2008. Using building energy simulation and geospatial modeling techniques to determine high resolution building sector energy consumption profiles. Energy Build. 40(8), 1426-1436.

Herold M., Hemphill J., Dietzel C., Clarke K.C, 2005, Remote sensing derived mapping to support urban growth theory, Proceedings of ISPRS, vol. XXXVI8/W27., 6p., California, USA.

Levine M.D., Nazif A.M., 1985. Dynamic Measurement of Computer Generated Image Segmentations. Pattern Analysis and Machine Intelligence, IEEE Transactions on PAMI-7, 155-164.

Loriot P., 2008. Etude expérimentale: détermination d'un MOS et calcul d'une tache urbaine à partir de la BD TOPO® d'IGN. CETE du Sud Ouest, 70p

Okada S.; Takai N., 2000, Classifications of Structural Types and Damage Patterns of Buildings for Earthquake Field Investigation. In Proceedings of the 12th World Conference on Earthquake Engineering, Auckland, New Zealand.

Puissant A., 2003. Information géographique et images à très haute résolution: utilité et application en milieu urbain. Thèse de doctorat, Université Louis Pasteur Strasbourg I, Strasbourg, France.

Puissant A., Hirsch J., Weber C., 2005. The utility of texture analysis to improve per-pixel classification for high to very high spatial resolution imagery. International Journal of Remote Sensing, 26(4), 733745.

Puissant A., Rougier S., Stumpf A., 2014. Objectoriented mapping of urban trees using Random Forest classifiers. International Journal of Applied Earth Observation and Geoinformation, 26, 235-245.

Vapnik V.N., 1998. Statistical Learning Theory. Wiley(Ed.), 768p, New York.

Vermote E.F., Tanre D., Deuze J.L., Herman M., Morcette J.-J., 1997. Second Simulation of the Satellite Signal in the Solar Spectrum, 6S: an overview. IEEE Transactions on Geoscience and Remote Sensing, 35, 675-686. 